\title{
Antitumor effects of oncolytic herpes simplex virus type 2 against colorectal cancer in vitro and in vivo
}

\author{
Lei Yin ${ }^{1-3}$ \\ Chunhong Zhao ${ }^{3}$ \\ Jixia $\mathrm{Han}^{4}$ \\ Zengjun $\mathrm{Li}^{2}$ \\ Yanan Zhen ${ }^{3}$ \\ Ruixue $\mathrm{Xiao}^{3}$ \\ Zhongfa $\mathrm{Xu}^{3}$ \\ Yanlai Sun ${ }^{2}$
}

'School of Medicine and Life Sciences, University of Jinan-Shandong Academy of Medical Sciences, Jinan, ${ }^{2}$ Department of Gastrointestinal Cancer Surgery, Shandong Cancer Hospital Affiliated to Shandong University, Shandong Academy of Medical Sciences, Jinan, ${ }^{3}$ Department of Gastrointestinal Surgery, The Affiliated Hospital of Shandong Academy of Medical Sciences, Jinan, ${ }^{4}$ Department of General Surgery, The Sixth People's Hospital of Jinan, Jinan, People's Republic of China
This article was published in the following Dove Press journal:

Therapeutics and Clinical Risk Management

7 February 2017

Number of times this article has been viewed

Background: The incidence of colorectal cancer (CRC) is on the rise. Furthermore, late-stage diagnoses and limited efficacious treatment options make CRC a complex clinical challenge. Therefore, a new therapeutic regimen with a completely novel therapeutic mechanism is necessary for CRC. In the present study, the therapeutic efficacy of oncolytic herpes simplex virus type 2 (oHSV2) in CRC was assessed in vitro and in vivo. oHSV2 is an oncolytic agent derived from herpes simplex virus type 2 that encodes granulocyte-macrophage colony-stimulating factor.

Materials and methods: We investigated the cytopathic effects of oHSV2 in CRC cell lines using the MTT assay. Then, cell cycle progression and apoptosis of oHSV2 were examined by flow cytometry. We generated a model of CRC with mouse CRC cell CT26 in BALB/c mice. The antitumor effects and adaptive immune response of oHSV2 were assessed in tumor-bearing mice. The therapeutic efficacy of oHSV2 was compared with the traditional chemotherapeutic agent, 5-fluorouracil.

Results: The in vitro data showed that oHSV2 infected the CRC cell lines successfully and that the tumor cells formed a significant number of syncytiae postinfection. The oHSV2 killed cancer cells independent of the cell cycle and mainly caused tumor cells necrosis. The in vivo results showed that oHSV2 significantly inhibited tumor growth and prolonged survival of tumor-bearing mice without weight loss. With virus replication, oHSV2 not only resulted in a reduction of myeloid-derived suppressor cells and regulatory $\mathrm{T}$ cells in the spleen, but also increased the number of mature dendritic cells in tumor-draining lymph nodes and the effective $\mathrm{CD}^{+} \mathrm{T}$ and $\mathrm{CD}^{+} \mathrm{T}$-cells in the tumor microenvironment.

Conclusion: Our study provides the first evidence that oHSV2 induces cell death in CRC in vitro and in vivo. These findings indicate that oHSV2 is an effective therapeutic cancer candidate that causes an oncolytic effect and recruits adaptive immune responses for an enhanced therapeutic impact, thus providing a potential therapeutic tool for treatment of CRC.

Keywords: colorectal cancer, oncolytic virus, herpes simplex virus type 2, granulocytemacrophage colony-stimulating factor, immunotherapy, gene therapy

\section{Introduction}

Colorectal cancer (CRC) is an aggressive malignancy, the incidence of which has shown a continuous upward trend. ${ }^{1} \mathrm{CRC}$ patients with distant metastases have a $12 \%$ survival rate. ${ }^{2}$ Greater than $20 \%$ of CRC patients have metastatic disease at the time of diagnosis, ${ }^{3}$ thus making CRC the fourth most common cause of cancer-related deaths. ${ }^{4}$ Currently, treatment approaches for CRC include the following: surgical intervention when possible, chemotherapy, and targeted drug therapy. ${ }^{5}$ Localized tumors with surgical resection can improve patient survival, but this simply means macroscopic 
clearance. $^{3}$ Greater than one-half of CRC patients will develop metastases due to the presence of micrometastases at the time of surgery. ${ }^{6}$ Chemotherapy can be used as neoadjuvant chemotherapy or adjuvant postoperative chemotherapy. Only a minority of CRC patients will benefit from chemotherapy because of modest efficacy or ineffectiveness against distant metastases. ${ }^{7}$ In addition, toxic effects, such as immune suppression caused by chemotherapeutic agents, can result in chemotherapy resistance to the tumor. ${ }^{8}$ Other targeted therapies, like antiangiogenic therapies or epidermal growth factor receptor inhibitors, have a moderate effect on CRC, and the resistance to therapies leads to worse prognosis. ${ }^{9}$ Therefore, the limitations of effective therapies in treating CRC patients necessitate the therapeutic progress of novel approaches for treatment of CRC.

In the last few years, cancer virotherapy has emerged as a promising therapeutic platform. On October 27, 2015, the oncolytic herpes simplex virus (T-VEC) was officially approved by the US Food and Drug Administration for use in melanoma patients. ${ }^{10}$ Unlike conventional cancer therapeutic modalities, oncolytic viruses (OVs) treatment of malignant tumors has unique attributes. OVs are naturally occurring or genetically engineered viruses that selectively damage malignant cells. When the virus is infected, it can release progeny virions that reinfect neighboring tumor cells and generate antitumor immunity that eliminates metastasized tumor cells with minimum harm to the normal tissue. ${ }^{11}$ Among various different viruses, herpes simplex virus type 2 (HSV-2) has some unique characteristics. First, HSV-2 has a domain that can activate the Ras/MEK/MAPK mitogenic pathway and induce c-Fos, which is required for efficient HSV-2 replication. ${ }^{12}$ Second, HSV-2 secretes glycoprotein G, and forms the virion host shut-off protein, which is involved in evading host innate immunity against viral infection. ${ }^{13}$ Third, infection with HSV-2 could induce syncytial formation in tumor cells, which provides an additional oncolytic mechanism that enhances an overall antitumor effect. ${ }^{14}$ Fourth, the HSV-2 OV, FusOn-H2, can effectively eliminate tumor cells at a lower multiplicity of infection (MOI) for increased safety. Fifth, $90 \%$ of adults carry antibodies to HSV-1 so that the host immune response theoretically increases virus clearance initially, but this may avoid HSV-2.

Oncolytic herpes simplex virus type 2 (oHSV2), a conditionally replication-competent $\mathrm{HSV}-2$, was generated by both ICP34.5 and ICP47 gene deletion and insertion of granulocyte-macrophage colony-stimulating factor (GM-CSF). Deletion of the ICP34.5 gene was introduced to confer selective oncolytic activity and reduced pathogenicity. ${ }^{15,16}$ ICP47 gene deletion promotes both antigen presentation and oncolytic selectivity, and allows for improved antitumor immunity and greater tumor killing. ${ }^{17}$ GM-CSF is a pleiotropic cytokine secreted by many kinds of cells. It produces multiple immunostimulatory effects, is involved in recruiting and activating dendritic cells (DCs), and induces tumor-specific cytotoxic T lymphocytes. In the construction of OVs, GM-CSF is the most widely used immune costimulatory molecule that has been introduced into several oncolytic viral vectors ${ }^{18}$ and shown to have a good therapeutic effect. ${ }^{19,20}$

It is generally known that cancers evolve multiple mechanisms of immune evasion and suppression. ${ }^{21}$ The suppressor cell populations can induce functional tolerance of activated $\mathrm{T}$ cells and/or block effector $\mathrm{T}$ cells. ${ }^{22,23}$ Regulatory $\mathrm{T}$ cells (Tregs) and myeloid-derived suppressor cells (MDSCs) are the two major immunosuppressive cell types mainly involved in tumor-induced immunosuppression. Thus, successful cancer immunotherapy will only be achieved when associated with the elimination of suppressive cells and improve antitumor immune effector cells, such as DCs and T lymphocytes. ${ }^{24}$ In the present study, we assessed in vitro cytotoxicity as well as the in vivo antitumor effect and immunostimulatory efficacy on effector and regulatory function of oHSV2 in a murine colorectal cancer model.

\section{Materials and methods Construction of recombinant HSV-2 expressing GM-CSF}

The oHSV2 was provided by Wuhan Binhui Bioscience and Technology Ltd. (Wuhan, People's Republic of China). oHSV2 is an attenuated, replication-competent oncolytic HSV-2, the construction of which has been previously described. ${ }^{25}$

\section{Cell lines and reagents}

Human LoVo, HCT116, and HT29 cell lines were provided by the Basic Science Laboratory of Shandong Cancer Hospital Affiliated with Shandong University (Jinan, People's Republic of China). CT26 is a murine colorectal adenocarcinoma cell line derived from BALB/c mice. CT26 was purchased from the Cell Bank of Shanghai Institute for Biological Sciences of the Chinese Academy of Sciences (Shanghai, People's Republic of China). Cells were cultured in Dulbecco's Modified Eagle's Medium or Roswell Park memorial Institute-1640 supplemented with $10 \%$ fetal bovine serum, $4 \mathrm{mmol} / \mathrm{L}$ glutamine, $100 \mathrm{of} \mu \mathrm{g} /$ $\mathrm{mL}$ penicillin, and $100 \mu \mathrm{g} / \mathrm{mL}$ of streptomycin under an atmosphere of $95 \%$ air and $5 \% \mathrm{CO}_{2}$ at 37 degree. 5-fluorouracil (5-FU) was purchased from Medchem Express ${ }^{\circledR}$ (ChemSpider, Monmouth Junction, NJ, USA) and dissolved 
in dimethyl sulfoxide (DMSO) at $20 \mathrm{mg} / \mathrm{mL}$. The final concentrations added to cells had $<0.5 \%$ DMSO, which is nontoxic to cells.

\section{Virus-mediated cytotoxicity assays}

The cytopathic effect was evaluated by viral cytotoxicity, cell cycle progression, and apoptosis analysis. The effect of oHSV2 on the proliferation of cancer cell lines was evaluated using the MTT assay (AMRESCO LLC, Solon, OH, USA) according to the manufacturer's instructions. Cell viability was determined by measuring absorbance at $570 \mathrm{~nm}$ with a reference of $630 \mathrm{~nm}$ using a microplate reader (BIO-RAD, Hercules, CA, USA). The controls on each day were set at $100 \%$ viability. The percentage cell survival rate treated with oHSV2 was calculated using the following formula: $(100 \% \times$ [absorbance value of experimental cells]/[absorbance value of control cells]). All measurements were performed in triplicate.

\section{Cell cycle and cell apoptosis detection}

For cell cycle detection, CT26 and LoVo cells were seeded at a concentration of $4 \times 10^{5}$ cells/well in 6-well plates. Cells were harvested at 24 or $48 \mathrm{~h}$ posttreatment with oHSV2 (MOI $=0.5$ and 1.0 ) or $5-\mathrm{FU}(0.1 \mu \mathrm{g} / \mathrm{mL}$ and $0.3 \mu \mathrm{g} / \mathrm{mL}$ for CT26; and $0.5 \mu \mathrm{g} / \mathrm{mL}$ and $1.0 \mu \mathrm{g} / \mathrm{mL}$ for LoVo) or phosphatebuffered saline (PBS). We used a cell cycle detection kit (CWBIO Clontech, Mount View, CA, USA) for chromosome staining according to the manufacturer's instructions. After incubation for $30 \mathrm{~min}$ at $37^{\circ} \mathrm{C}$, the cells were analyzed with BD FACSCalibur ${ }^{\mathrm{TM}}$ (BD, Lake Franklin, NJ, USA). Apoptosis was quantified by detecting surface exposure of phosphatidylserine in apoptotic cells using the Annexin V-FITC/PI apoptosis detection kit (CWBIO Clontech). CT26 and LoVo cells were infected for $48 \mathrm{~h}$ with oHSV2 (MOI $=0.5$ and 1.0), and apoptotic cells were detected according to the manufacturer's instructions using BD FACSCalibur.

\section{Animal experiments}

The Committee of Animal Care and Use of the Shandong Cancer Hospital affiliated to Shandong University approved the experimental protocol. Mice were treated according to the National Institutes of Health guidelines. The protocol was approved by the Committee on the Ethics of Animal Experiments of the Shandong Cancer Hospital affiliated to Shandong University. All mice were bred in a standard environment and were given free access to food and water. To evaluate and compare the antitumor activity of oHSV2 in vivo, a colorectal cancer tumor model was established in immunocompetent BALB/c mice. Fifty-four female mice, 5 weeks of age, were purchased from the Shandong
Experimental Animal Center (Shandong, People's Republic of China). To establish subcutaneous tumors, $5 \times 10^{5}$ CT26 cells in $100 \mu \mathrm{L}$ of normal PBS were subcutaneously injected into the right flank of each mouse. When tumors reached a mean diameter of 6-7 $\mathrm{mm} 7$ days after injection, mice were randomly assigned to 1 of 3 groups receiving PBS, 5-FU, and oHSV2. The groups were treated as follows: 1) 5-FU alone on days 0 and $6 ; 2$ ) oHSV2 alone on days 0,2 , 4, and 6; and 3) control treatment of PBS on days $0,2,4$, and 6. For oHSV2, $1 \times 10^{6} \mathrm{PFU}$ were applied by direct intratumoral (IT) injection, PBS $(100 \mu \mathrm{L})$ was injected IT, and 5-FU was applied at a dose of $75 \mathrm{mg} / \mathrm{kg}$ by intraperitoneal injection. The 5-FU dose was based on a review of the literature and preexperimental effectiveness. ${ }^{26,27}$ After initiation of drug administration, tumor dimensions and body weight were measured every 4 days for 28 days and tumor volume (V) was estimated using the following formula: $V=1 / 2 \mathrm{ab}^{2}$, where $\mathrm{a}=$ tumor major diameter and $\mathrm{b}=$ tumor minor diameter. All mice were followed for survival for 60 days.

\section{GM-CSF quantification by ELISA}

Each group included five randomly selected rats for quantification of GM-CSF expression. Blood was collected via the orbital vein $2,4,6,8,10,15$, and 20 days after the first oHSV2 application. Serum was centrifuged at 4,000 rpm for $5 \mathrm{~min}$ and stored at $-20^{\circ} \mathrm{C}$. GM-CSF concentration was determined by an enzyme-linked immunosorbent assay (ELISA; R\&D Systems, Wiesbaden, Germany) according to the manufacturer's protocol.

\section{Characterization of MDSC, Tregs in spleens, DCs in tumor-draining lymph nodes, and $\mathrm{CD}^{+}{ }^{+}$and $\mathrm{CD} 8{ }^{+} \mathrm{T}$-cells in tumors using flow cytometric analysis}

Tumor-challenged mice were treated as described earlier, and on day 10 after the first treatment, mice from each group $(n=3)$ were euthanized and the cells from the spleens, tumor-draining lymph nodes (TDLNs), and tumors were surgically removed and used for MDSC, Treg, DC, and $\mathrm{CD}^{+}{ }^{+}$and $\mathrm{CD} 8^{+} \mathrm{T}$-cell quantification by flow cytometry. A single cell suspension of spleens and TDLNs was prepared by filtration through a 300-gauge mesh. Tumor suspensions were prepared as described previously, with modifications. ${ }^{28}$ The cell suspensions were then stained at 4 degree for 30 min using the following antibodies: FITC anti-mouse CD11b, PE anti-mouse Gr-1, FITC anti-mouse CD4, PE anti-mouse FOXP3, FITC anti-mouse CD11c, PE anti-mouse CD86, PE-cy5 anti-mouse CD3, FITC anti-mouse CD4, $\mathrm{PE}$ anti-mouse $\mathrm{CD} 8$, and the corresponding isotype control 
antibodies (all monoclonal antibodies were obtained from eBioscience). After washing with PBS, the cells were fixed with $10 \%$ formaldehyde. The cell frequency was determined using BD FACSCalibur. The samples were analyzed using FlowJo software (FlowJo, Ashland, OR, USA).

\section{Statistical analysis}

Statistical analysis was carried out using SPSS 17.0 (IBM Corp., Armonk, NY, USA). All continuous data were presented as the mean \pm standard deviation (SD). Comparisons of data in flow cytometry were performed using a two-tailed Student's $t$-test (unpaired) or two-way analysis of variance (ANOVA) with Tukey multiple comparisons. Survival was analyzed by Kaplan-Meier curves, and statistical analysis was conducted using Prism (GraphPad Software, Inc., San Diego, CA, USA). $P$-values $<0.05$ were considered statistically significant.

\section{Results}

\section{Cytotoxicity of oHSV2 on CRC cells}

The cytotoxic effect of oHSV2 was tested in human LoVo, HT29, and HCT116 cell lines and the murine CT26 cell line. As shown in Figure 1A, all four cell lines were sensitive to oHSV2-induced cytotoxicity. The tumor cell shape became rounded and suspended, the gap between cells increased, and the original shape was lost. After infection, oHSV2 caused all cancer cell lines to form a typical syncytium (Figure 1B), which was associated with strong induction of an antitumor immunologic effect. MTT analysis revealed that the percentage of living cells was decreased in a time- and dose-dependent manner (Figure 2A). We also used different doses of 5-FU as a positive control in vitro. As can be seen in Figure 2B, both treatments exhibited a concentration-dependent reduction in CT26 and LoVo cell viability. The cells treated with $0.5 \mu \mathrm{g} / \mathrm{mL}$ of $5-\mathrm{FU}$ for $48 \mathrm{~h}$ had cell viabilities of $66 \%$ and $72.7 \%$, respectively, and $35.3 \%$ and $46.3 \%$ viability after treatment with a $\mathrm{MOI}=5$, respectively.

\section{Effect on cell cycle and apoptosis}

To understand the underlying mechanisms of the cytopathic effect by oHSV2 treatment, we analyzed its effects on cell cycle phase distribution and cell apoptosis in LoVo and CT26 cells. As shown in Figure $3 \mathrm{~A}$ and B, treatment with 5-FU had a marked effect on $\mathrm{S}$ phase frequency compared with the control group (all $P<0.05$ ). The G0/G1 phase frequency was significantly decreased compared with the control group (all $P<0.05)$. Treatment with oHSV2 had no effect on the G0/
G1, G2/M, or S phase compared with the control group (all $P>0.05$ ). This finding implies that oHSV2 infected and killed tumor cells independent of the cell cycle phase, whereas 5-FU mainly blocked cancer cells that were in the $\mathrm{S}$ phase. The Annexin-V/PI assay showed that infection with oHSV2 caused a greater proportion of necrotic cells compared with the control group (all $P<0.05$ ) in a dose-dependent manner (Figure 3C and D). The percentage of early apoptotic cells was very low, and there was no statistical difference when compared with the control group. oHSV2 induced necrosis in tumor cells, but not apoptosis.

\section{Expression of GM-CSF in vivo}

In the CT26 xenograft model, the expression of GMCSF in blood was detected on the 2nd day after initial IT injection with oHSV2. The level of GM-CSF was continuously elevated and the peak values were found

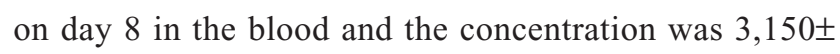
$327.1 \mathrm{pg} / \mathrm{mL}$. Then, the level of GM-CSF expression was gradually decreased on day 10 (Figure 4). As expected, there was no GM-CSF secretion in the PBS and 5-FU groups. The results suggest that oHSV2 enhanced GMCSF gene expression.

\section{oHSV2 treatment affected mouse immunity compared with 5-FU treatment}

To explore possible cellular mechanisms of the enhanced antitumor effect mediated by GM-CSF-armed HSV-2 treatment in immunocompetent $\mathrm{BALB} / \mathrm{c}$ mice bearing the CT26 murine CRC tumor model, spleens, TDLN, and tumor tissues were collected for analysis of Tregs, MDSCs, DCs, and effector T cells after treatment by flow cytometry. As can be seen in Figure $5 \mathrm{~A}$ and $\mathrm{B}$, treatment with either 5 -FU or oHSV2 alone resulted in reductions on the MDSC frequency in the spleen $(7.84 \%$ and $2.50 \%$, respectively) compared with the control group $(14.60 \%, P<0.01)$, but oHSV2 was more effective than 5-FU in depleting MDSC. The mean frequency of Tregs was higher in the 5-FU group compared with the control group (14.50\% vs $8.94 \%$, $P<0.01$ ), but oHSV2-treated mice showed a slight reduction in Treg frequency $(4.60 \%, P<0.05)$. In the TDLN, the frequency of DCs was increased when treated with oHSV2 compared with the control group $(6.49 \%$ vs $3.73 \%, P<0.01$; Figure 5C and D). A significantly lower frequency of DCs was found following 5 -FU treatment $(2.04 \%, P<0.05)$. Therefore, oHSV2 induced downregulation of MDSCs and Tregs, and upregulation of DCs. Similarly, flow cytometric analysis of the frequency of T lymphocytes in tumor tissues 
A
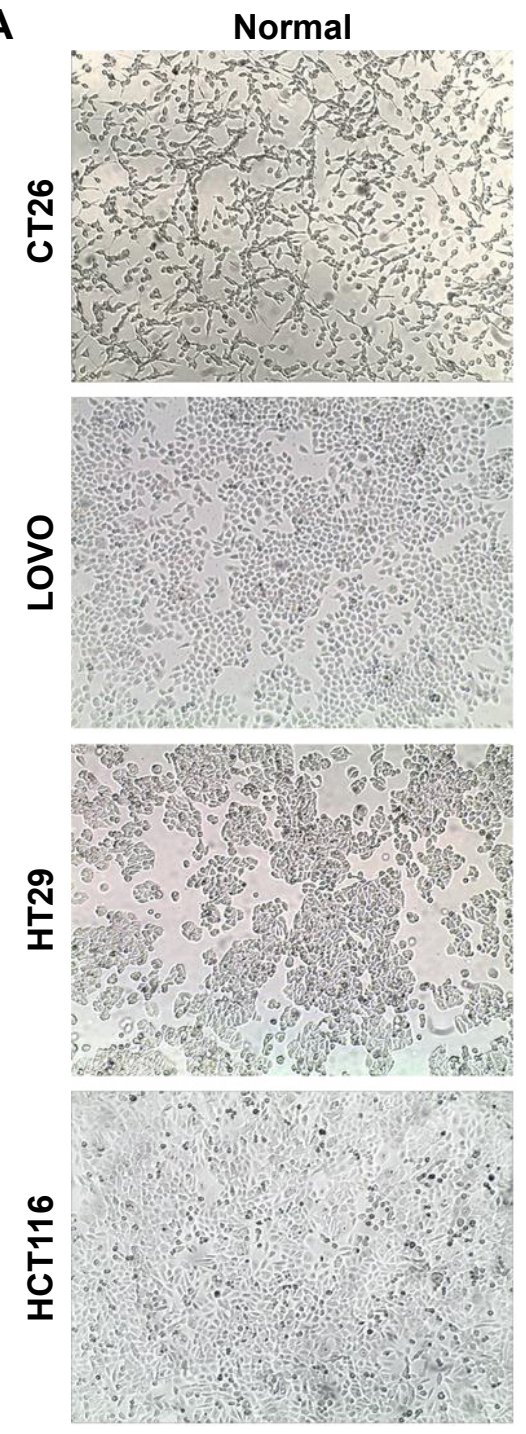

B

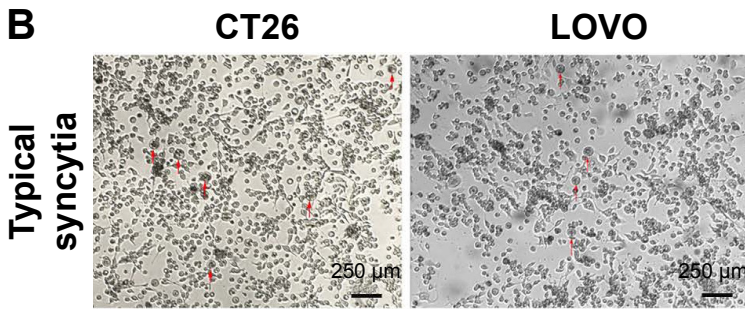

$48 \mathrm{~h}$
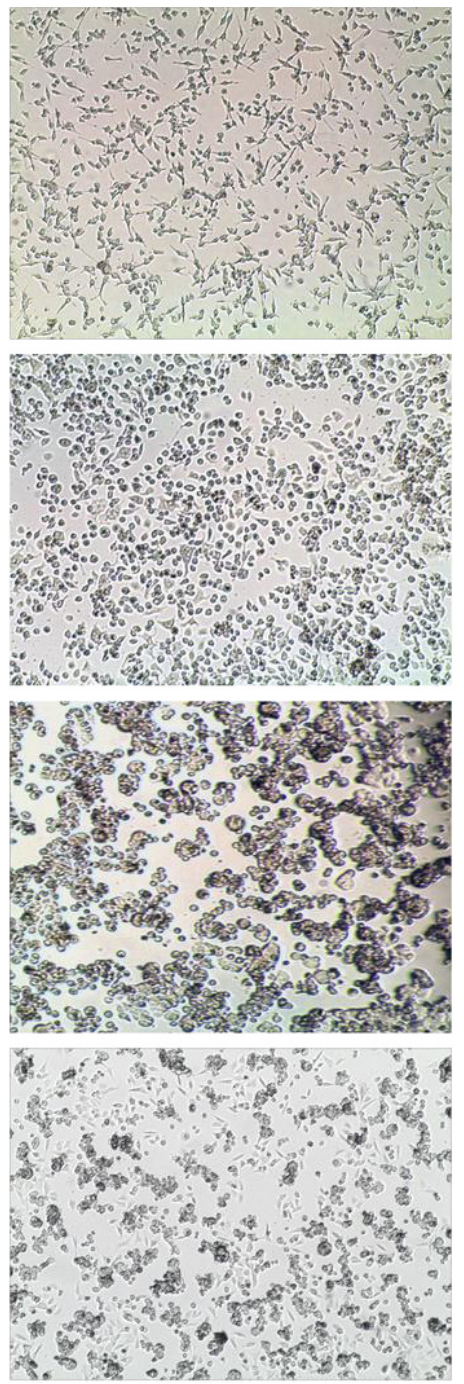

$60 \mathrm{~h}$
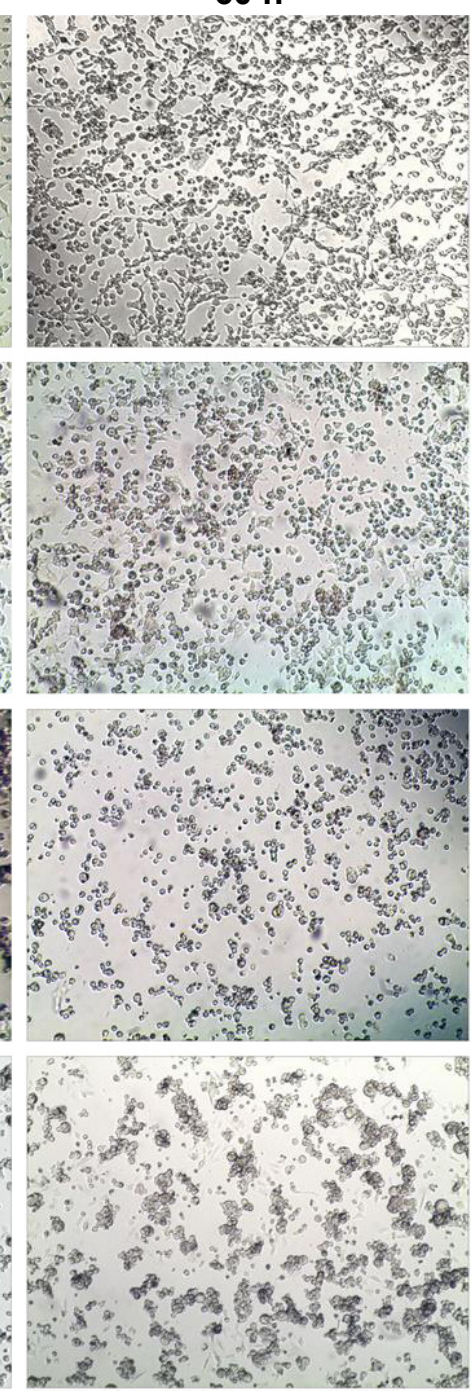

Figure I Oncolytic effect of oHSV2.

Notes: (A) The antitumor effects of oHSV2 in various colorectal cancer cell lines. Human murine CT26, LOVO, HT29 and HCTI I 6 cell lines infected by oHSV2 at MOI =I.0. After the indicated time points, OV shows effective killing on tumor cells. (Images were observed with an inverted phase contrast microscope at $40 \times$ objective magnification.) (B) oHSV2 was used to infect various colorectal cancer cells at $\mathrm{MOI}=1.0$; typical syncytia were observed after $48 \mathrm{~h}$ of treatment. (Images were observed with an inverted phase contrast microscope at $40 \times$ objective magnification.)

Abbreviations: oHSV2, oncolytic herpes simplex virus type 2; MOI, multiplicity of infection; OV, oncolytic virus.

was obtained. Data from one representative experiment in which the percentage of $\mathrm{CD} 4^{+}$and $\mathrm{CD} 8^{+} \mathrm{T}$-cells from the oHSV2-treated group was significantly higher than mock-treated tumors is demonstrated in Figure 5C (15\% vs $8.57 \%, P<0.01 ; 8.19 \%$ vs $5.15 \%, P<0.01$; Figure $5 \mathrm{D})$. 5 -FU treatment appeared to reduce the proportion of $\mathrm{CD} 4^{+}$ and $\mathrm{CD} 8^{+} \mathrm{T}$-cell levels $(4.17 \%$ and $2.98 \%$, respectively; all $P<0.05)$ compared with the control group. Together, these data suggest that oHSV2 successfully reduced the number of immunosuppressive cells and enhanced specific antitumor immune responses of mice bearing tumors, which differed from 5-FU. 

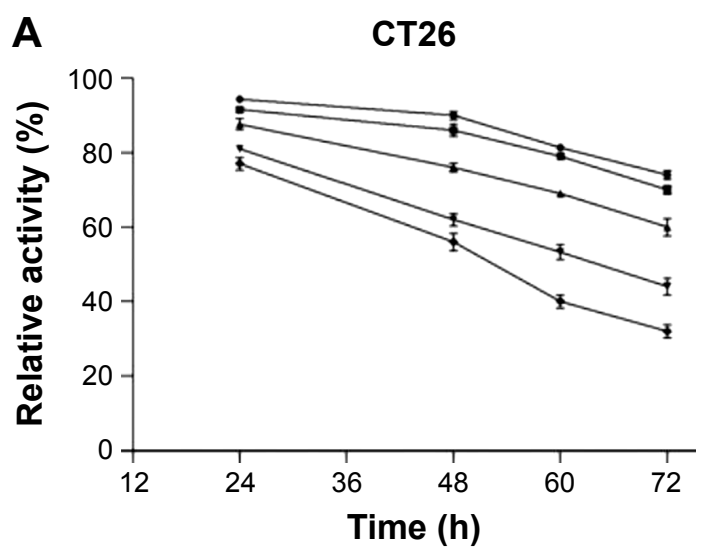

$\rightarrow \mathrm{MOI}=0.3 \rightarrow \mathrm{MOI}=0.5$

B
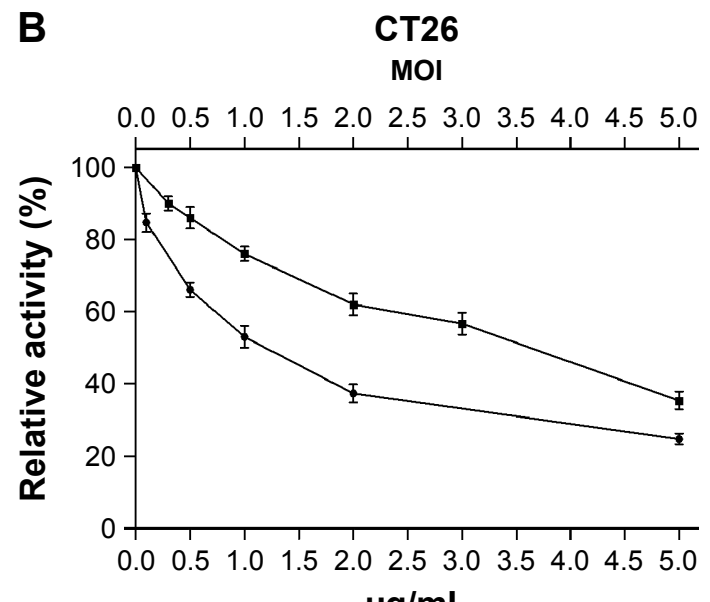

$\mu \mathrm{g} / \mathrm{mL}$
LOVO
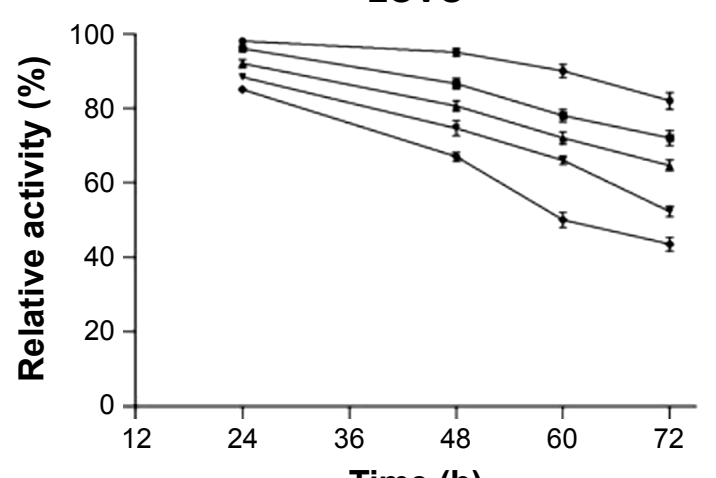

Time (h)

$-\mathrm{MOI}=1.0 \rightarrow \mathrm{MOI}=2.0 \rightarrow \mathrm{MOI}=3.0$

LOVO

MOI

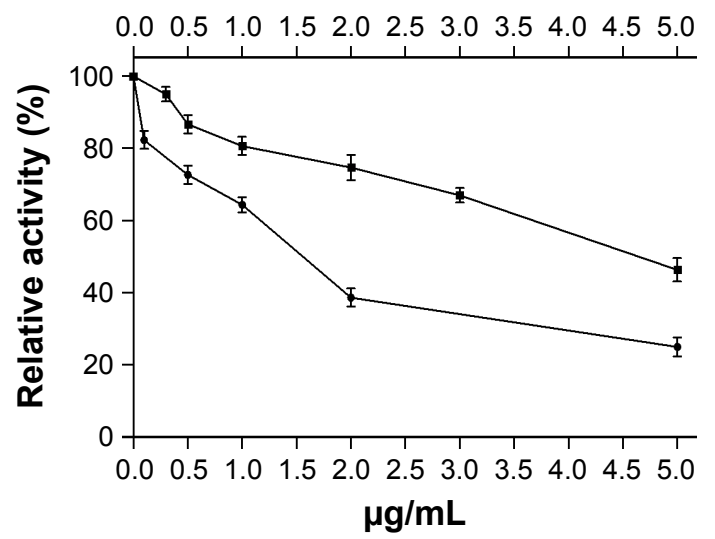

$\rightarrow-$ oHSV2 $\multimap 5-F U$

Figure 2 The cell viability of cancer cell was examined by using the MTT assay.

Notes: (A) Cytotoxic effect of oHSV2 on CT26 and LOVO. Cancer cells were treated with oHSV2 at indicated MOI and time. Virus-induced cytotoxicity was assessed using the MTT assay. The oHSV2-mediated cytotoxicity was increased in a time- and dose-dependent manner. Each value represents the mean \pm SD of three independent samples. (B) The CT26 and LOVO cells were treated with oHSV2 of different MOls for $48 \mathrm{~h}$. 5-FU was used as a positive control. Each value represents the mean \pm SD of three independent samples.

Abbreviations: oHSV2, oncolytic herpes simplex virus type 2; MOI, multiplicity of infection; 5-FU, 5-fluorouracil; SD, standard deviation.

\section{oHSV2 inhibited the growth of subcutaneous CT26 xenografts without systemic side effects}

As expected, mice treated with 5-FU or oHSV2 alone demonstrated a prolonged median survival time compared with PBS-treated mice (median survival, 36 days for the control vs 51 days for 5-FU alone and 50 days for oHSV2 alone; $P<0.01$ for 5-FU and oHSV2 [log-rank test]). The median survival time between mice that received either treatment alone was not significantly different $(P=0.65$; Figure 6A). Four weeks following the initiation of treatment, tumors in the control group were significantly increased in size (approximately $2,197.67 \pm 121.97 \mathrm{~mm}^{3}$ ), while the tumor volume of the group treated with oHSV2 injection was $1,439.17 \pm 107.39 \mathrm{~mm}^{3}$ on day 28 after first therapy ( $P<0.01$ vs control). Interestingly, no statistical was observed between the 5-FU and oHSV2 treatment groups with respect to tumor volume $(P>0.05$; Figure 6B). These findings were consistent with the results of antitumor immunity analysis. We also observed the effects of different treatments on body weight in mice. As shown in Figure 6C, the group treated with 5-FU showed a continuous reduction in the body weight. On day 28 , the average body weight of the mice treated with 5-FU was $16.61 \pm 0.74 \mathrm{~g}$, which was significantly different from the other groups $(P<0.01)$. The body weight of the mice treated with oHSV2 increased slowly, and there was no statistically significant change compared with control groups $(21.16 \pm 0.68 \mathrm{~g}$ vs $22.07 \pm 0.54 \mathrm{~g}$, $P>0.05$ ). In addition, the mice treated with 5-FU appeared listless and showed reduced autonomic activity. However, these adverse effects did not appear in mice in oHSV2 group. 
Also, there was no necrosis and ulceration in the area of skin where the virus was injected. These results demonstrated that treatment with either 5-FU or oHSV2 exhibited significant anticancer effects and also showed that the oHSV2 did not influence the body weight of mice and that it was less toxic.

\section{Discussion}

At present, CRC remains difficult to cure and represents a complex and challenging clinical problem. The 5-year survival rate for metastatic colorectal cancer (mCRC) remains $<30 \%$ when treated with chemotherapy with or without surgery. ${ }^{29}$ The use of OVs is a promising therapeutic approach to fight cancer. OVs directly lyse tumor cells and some may induce systemic antitumor immunity, thus pointing to a novel therapeutic modality for CRC. In this report we present the efficacy of oHSV2, a conditional replication-competent OV encoding GM-CSF, for treating CRC. To observe the therapeutic effect of oHSV2 more
A
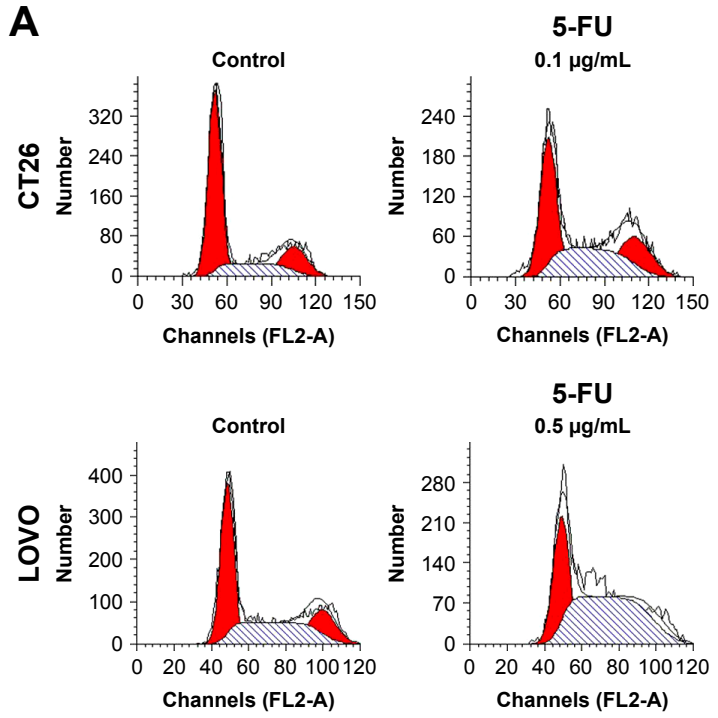

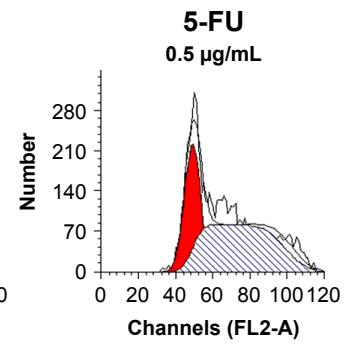

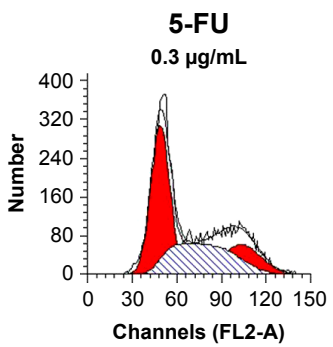

5-FU

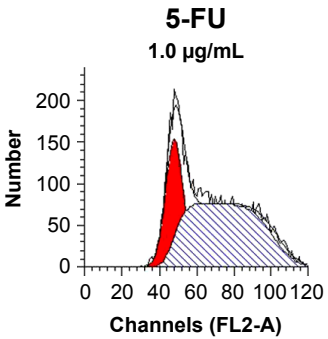

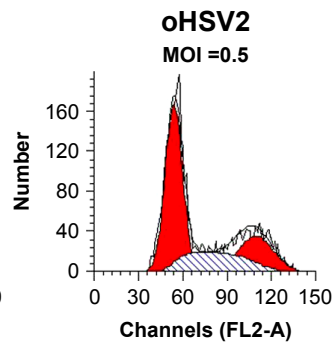
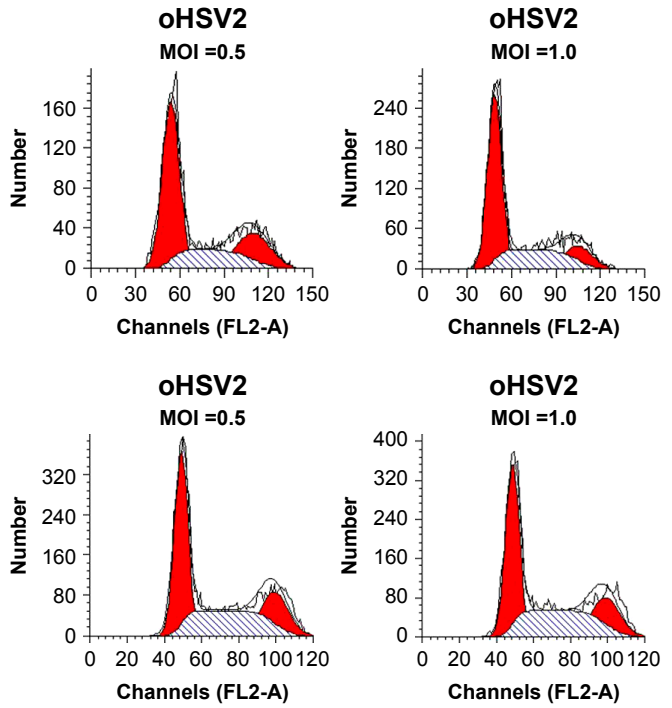

B
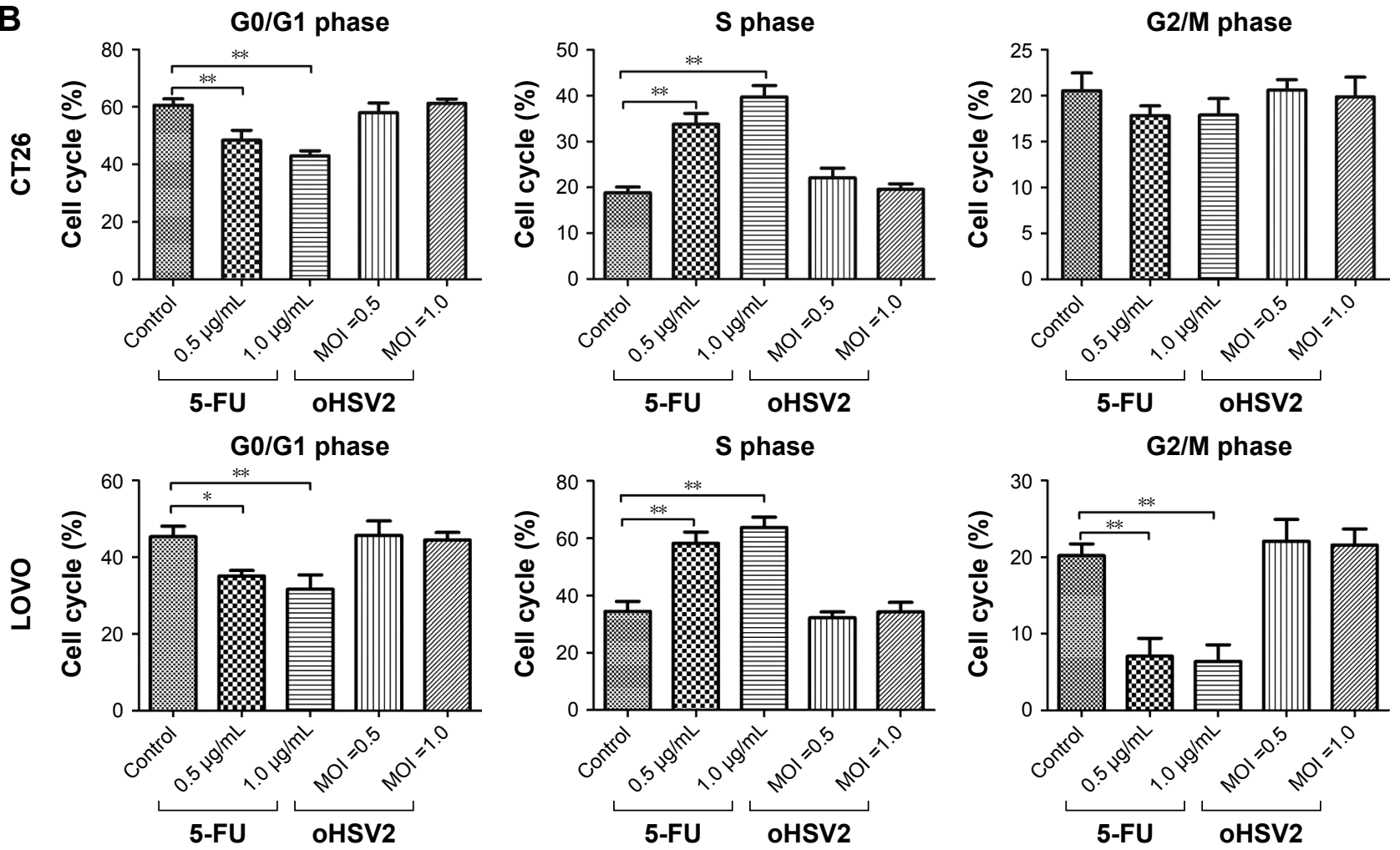

Figure 3 (Continued) 

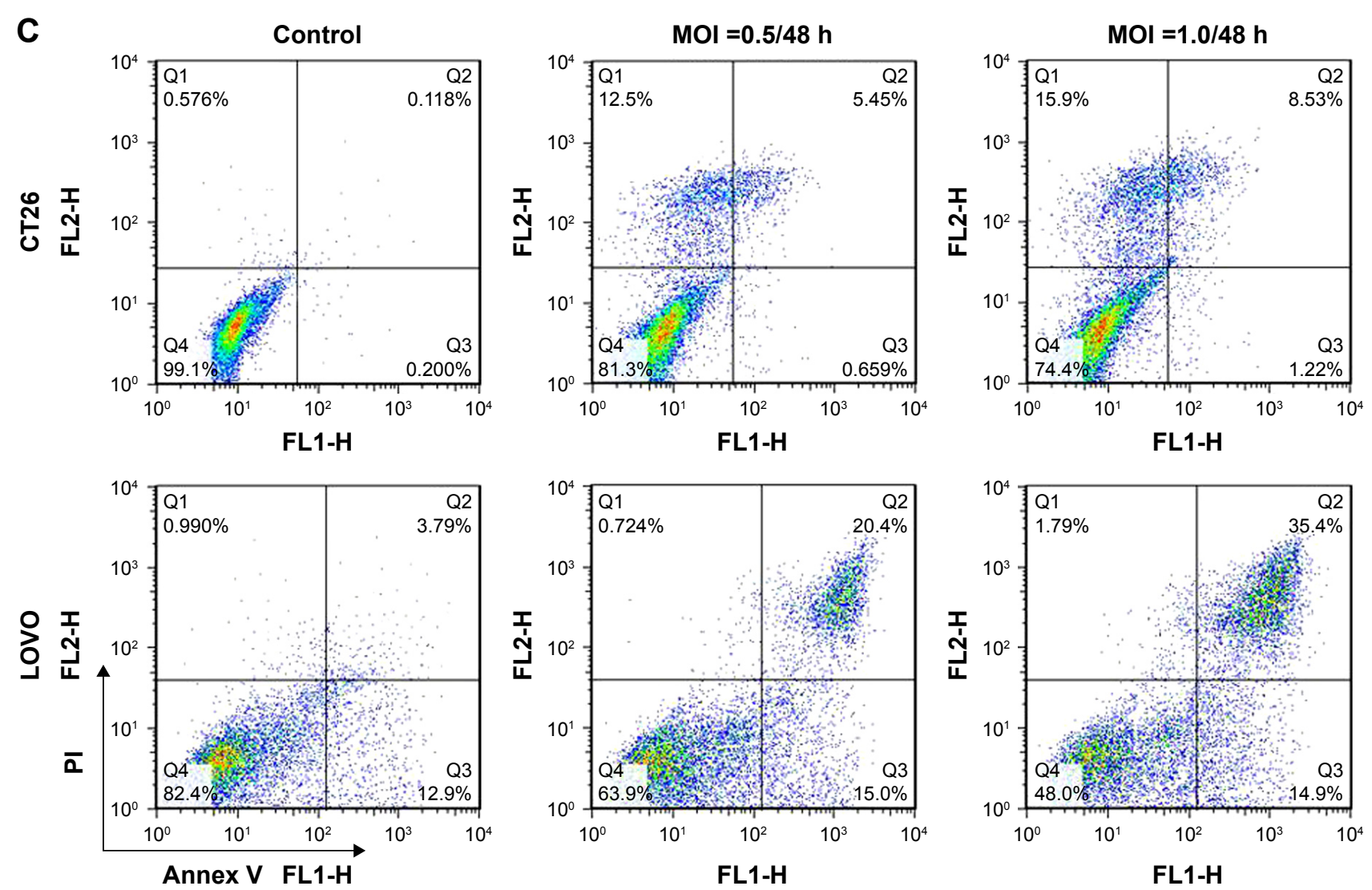

D
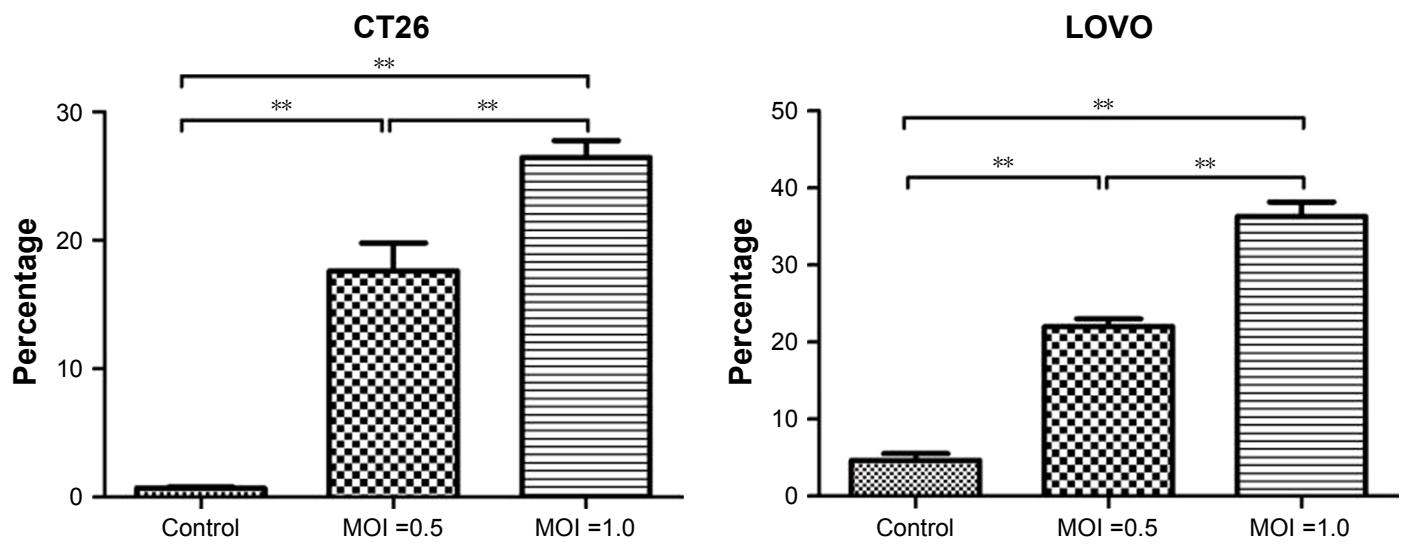

Figure 3 In vitro comparison of oHSV2 with 5-FU in cell cycle and apoptosis.

Notes: (A and B) Effects of oHSV2 infection after $48 \mathrm{~h}$ on cell cycle progression in CT26 and LOVO cells. Tumor cells were treated with oHSV2 or 5-FU or PBS, and then the distribution of cells in different phases of cell cycle was analyzed by flow cytometry after propidium iodide staining. The images show oHSV2 infection independent of cell cycle phase, whereas 5-FU induced S arrest with a marked increase of percentage of S cells. A: CT26, B: LOVO, ${ }^{*}>0.05$ significantly different vs PBS. (C and D) Induction of apoptosis in oHSV2-treated cells. CT26 and LOVO cells infected oHSV2 at the indicated MOI for $48 \mathrm{~h}$ by flow cytometric analysis. It leads to cancer cells necrosis in a dosedependent manner. However, there was no statistical difference in early stage of apoptosis. $* * P<0.01$. Each value represents the mean $\pm S D$ of three independent samples. Abbreviations: oHSV2, oncolytic herpes simplex virus type 2; MOI, multiplicity of infection; SD, standard deviation; 5-FU, 5-fluorouracil; PBS, phosphate-buffered saline.

directly, we used 5-FU as a positive control because it is a classic chemotherapy agent used in the treatment of CRC.

oHSV2 was able to efficiently infect and kill CRC cell lines, leading to cell oncolysis and growth stress. When tumor cells are lysed, tumor-associated antigens (TAAs) will be released into the tumor microenvironment, which could lead to a consolidating systemic antitumor response active against metastases. ${ }^{30}$ At the same time, we investigated cell viability after treatment with oHSV2 at different MOIs or 5-FU at different doses. The results showed that with an increase in MOI or dose, the activity of tumor cells gradually decreased. In addition, oHSV2 induction of all CRC cell lines caused syncytial formation in our study. It has been reported that syncytial formation induced by viral fusogenic glycoproteins can induce the release of large quantities of vesicles reminiscent of syncytiosomes, which can induce a 


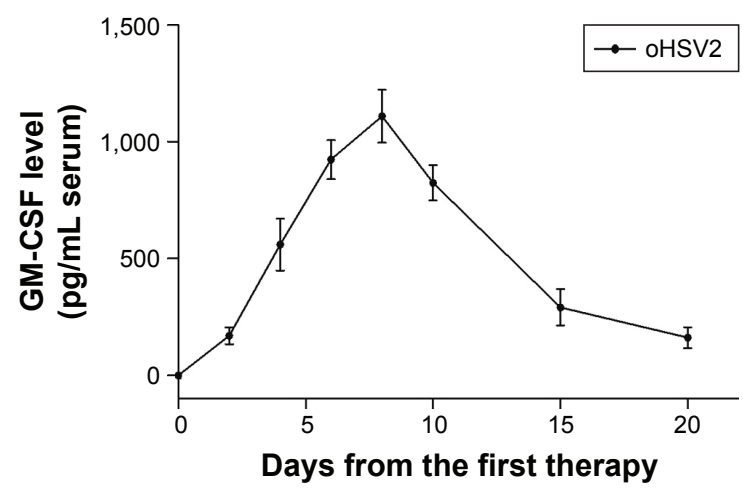

Figure 4 GM-CSF serum concentrations over time following intratumoral injection of oHSV2 in tumor-bearing mice.

Notes: BALB/c mice ( $\mathrm{N}=3$ per group) were treated with oHSV2, 5-FU, and PBS. Ten days after first therapy, spleens were harvested from the mice.

Abbreviations: GM-CSF, granulocyte-macrophage colony-stimulating factor; oHSV2, oncolytic herpes simplex virus type 2; 5-FU, 5-fluorouracil; PBS, phosphatebuffered saline. robust antitumor immune response. ${ }^{31,32}$ Chemotherapy drugs do not have this feature.

5-FU is metabolized to ribonucleotides and deoxyribonucleotides, which can be incorporated into RNA and DNA, respectively. Treatment of tumor cells with 5-FU leads to an accumulation of cells in the $\mathrm{S}$ phase and has been shown to induce apoptosis in sensitive cells. ${ }^{33,34}$ Therefore, 5-FU cannot eliminate all cancer cells and result in the induction of drug resistance. In contrast, the results of treatment of oHSV2 were cell cycle independent and induced tumor cells with necrosis. Cell death by necrosis is typically associated with inflammation in contrast to apoptosis. ${ }^{35}$ The aggregation of inflammatory cells may enhance the antitumor response. Therefore, our virus could kill tumor cells in all cell cycle phases, and oHSV2 induced necrosis
A
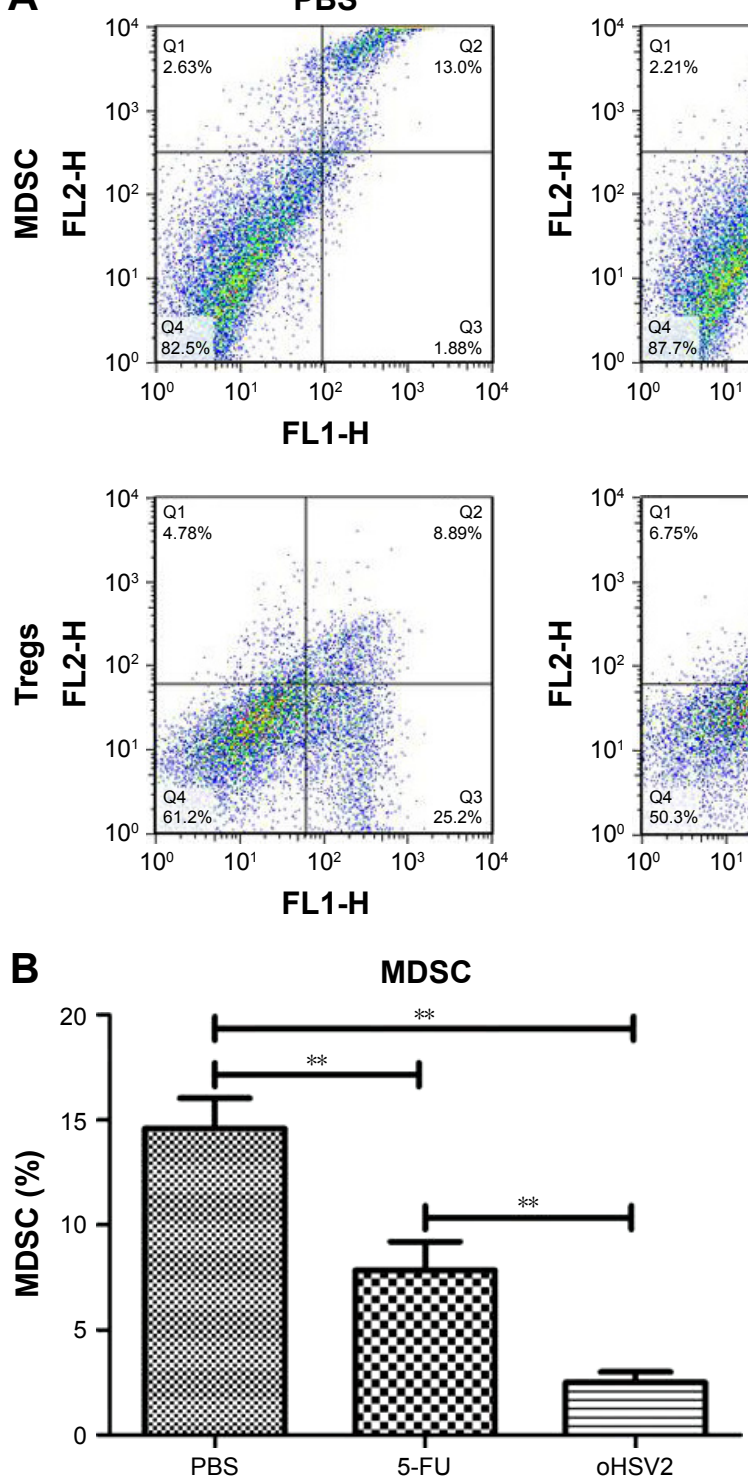

B

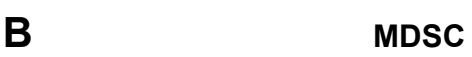

5-FU
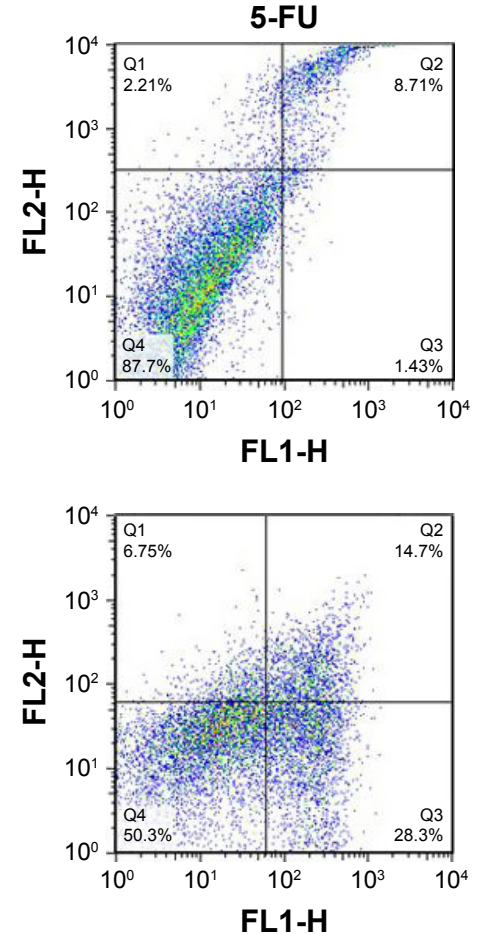
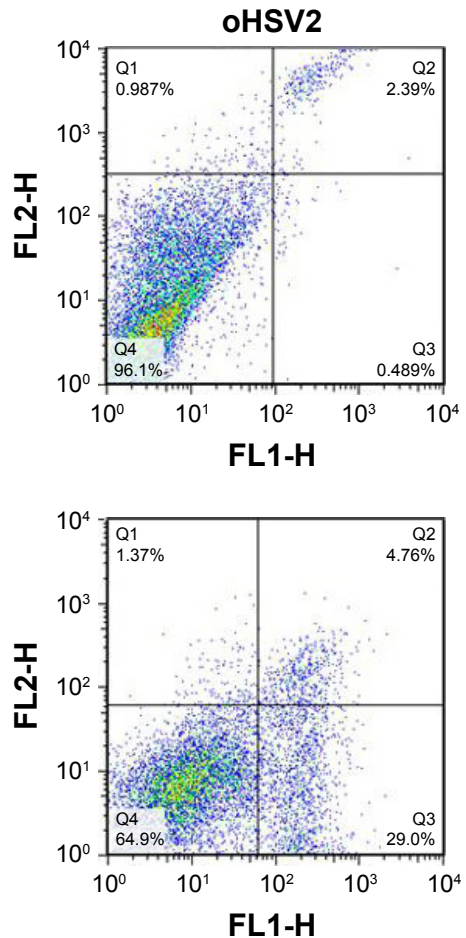

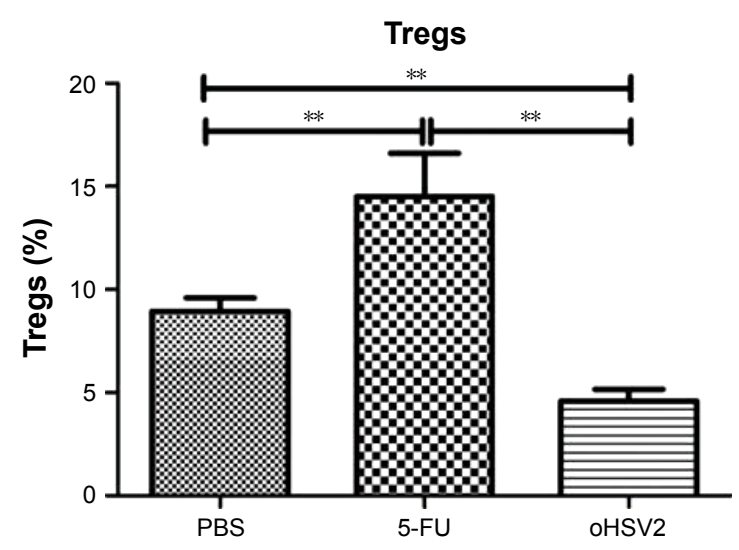

Figure 5 (Continued) 
C
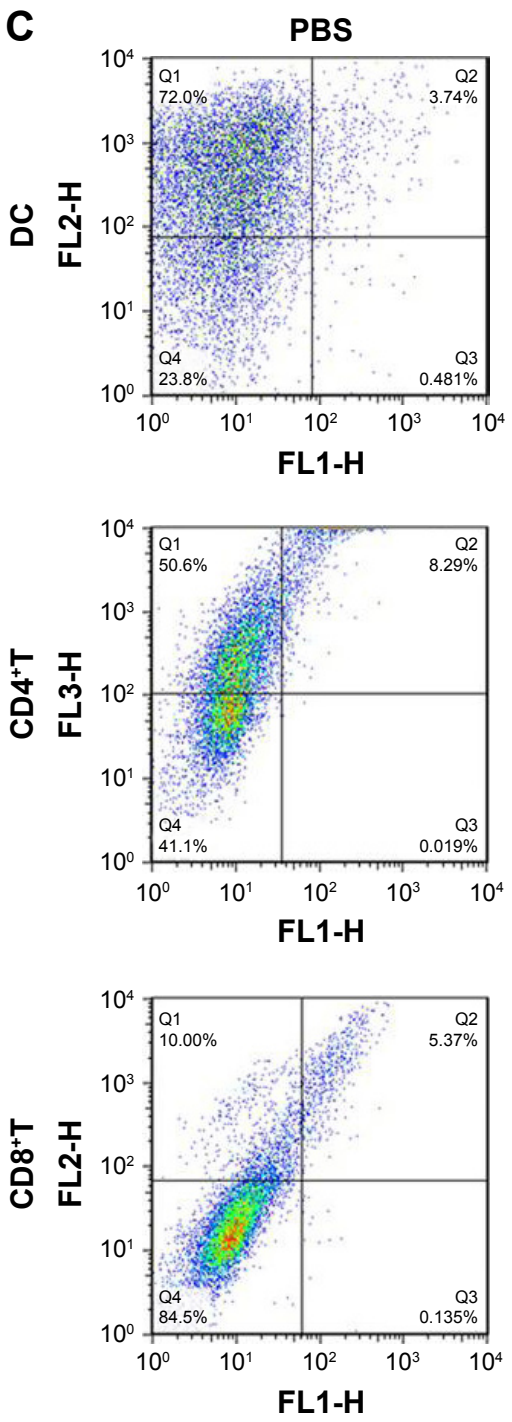

5-FU
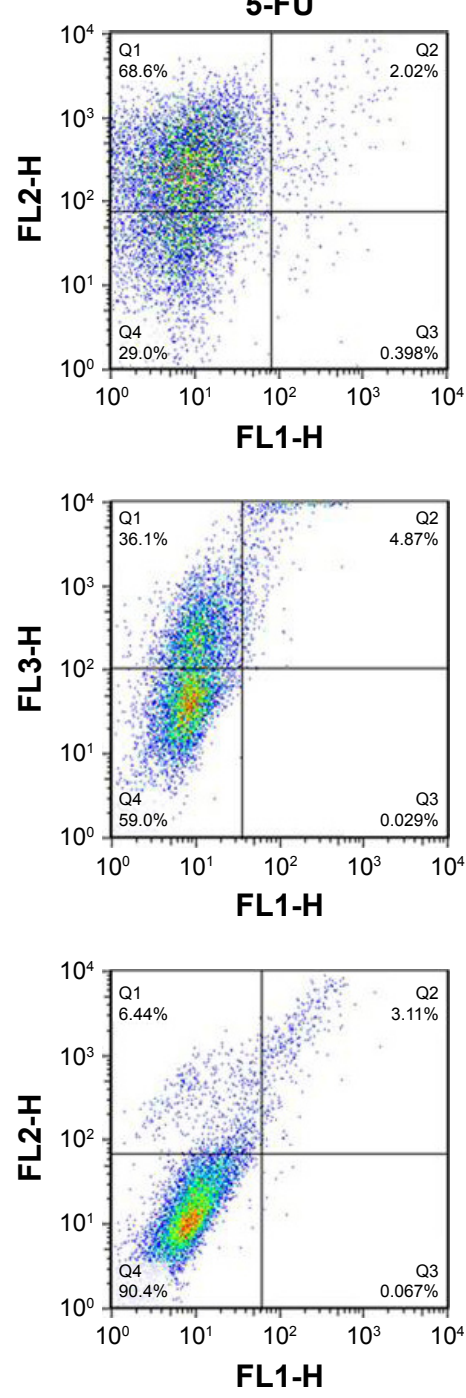

D

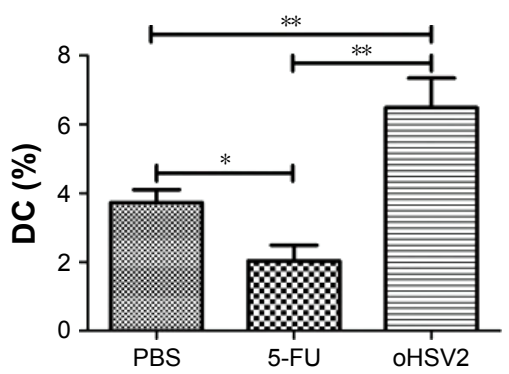

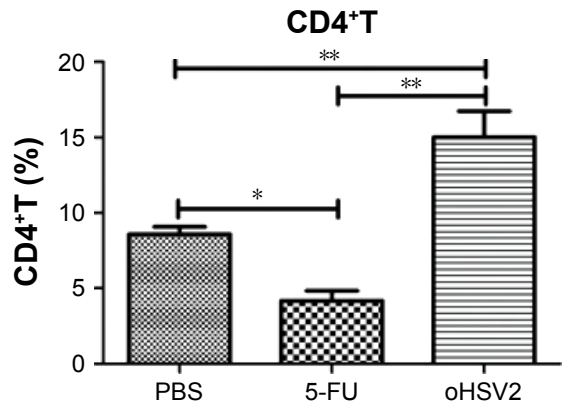
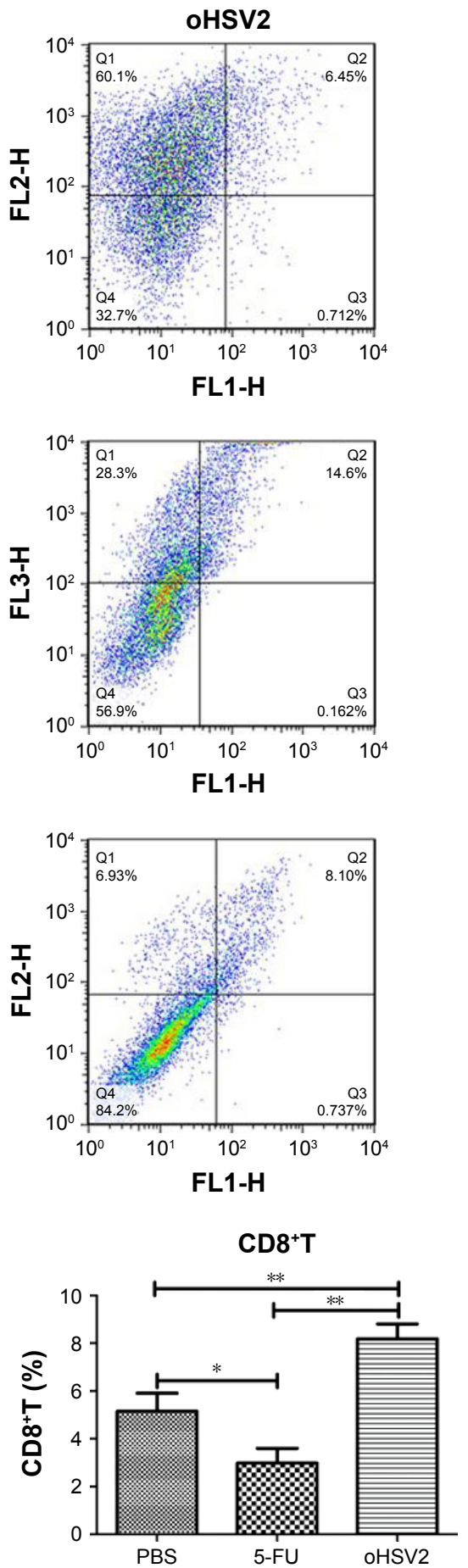

Figure 5 The oHSV2 increased the antitumor immunity in vivo.

Notes: (A) shows the flow cytometry analysis of one representative sample from each treatment group. (B) The image shows the percentage of MDSC and Tregs. Statistical significance was determined using one-way analysis of variance (ANOVA) (with Tukey's posttest) (**P $<0.0 \mathrm{I})$. Error bars represent standard error of the mean. BALB/c mice ( $\mathrm{N}=3$ per group) were treated with oHSV2, 5-FU, and PBS. Ten days after first therapy, TDLN and tumor were harvested from the mice. (C) shows the flow cytometry analysis of one representative sample from each treatment group. (D) The image shows the percentage of DCs in TDLN, CD4+T, and CD8 ${ }^{+} T$ in tumor. Statistical significance was determined using one-way ANOVA (with Tukey's posttest) $(* P<0.05, * * P<0.01)$. Error bars represent standard error of the mean.

Abbreviations: MDSC, myeloid-derived suppressor cells; Tregs, T regulatory cells; oHSV2, oncolytic herpes simplex virus type 2; 5-FU, 5-fluorouracil; PBS, phosphatebuffered saline; TDLN, tumor-draining lymph nodes; DC, dendritic cell.

in tumor cells, but not apoptosis, which is in agreement with a previous study. ${ }^{25}$

Currently, the tumor microenvironment is considered to be an immunosuppressive condition. Tumors can rapidly evolve immune evasion and immunosuppressive mechanisms countering clinical treatment, leading to treatment failure. ${ }^{36}$ Consequently, cancer immunotherapy strategies have attracted increased attention. Interestingly, tumors 

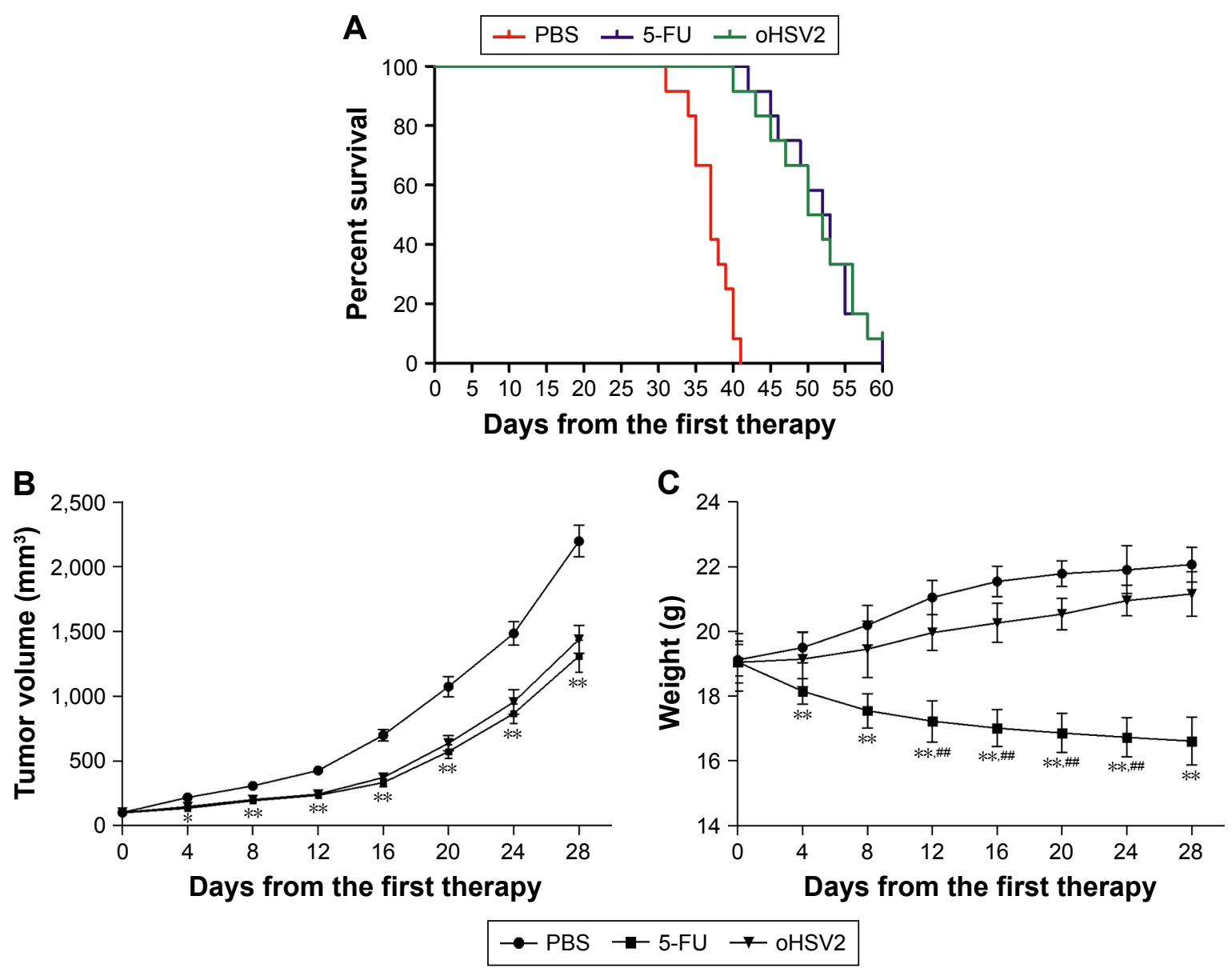

Figure 6 oHSV2 suppresses the growth of CT26 colorectal tumors in mice.

Notes: (A) Kaplan-Meier survival curve comparing overall survival among the three groups. Median time to tumor progression with oHSV2 was 50 days compared with 36 days with PBS alone $(P<0.0 \mathrm{I})$ and $5 \mathrm{I}$ days with 5 -FU alone $(P=0.6 \mathrm{I})$. Statistical significance was defined as $P<0.05$. (B) Subcutaneous $C T 26$ xenografts were established in $\mathrm{BALB} / \mathrm{c}$ mice and treated with injections of oHSV2, 5-FU, or PBS. The tumor volume of mice among the different groups was measured every 4 days following treatments. The data are represented as mean \pm SD. Results showed that oHSV2 significantly suppressed growth of $C T 26$ xenografts. $* P<0.05$ significantly different vs PBS, $* * P<0.01$ significantly different vs PBS. There was no statistical significance observed between the 5-FU-alone and oHSV2-alone treatment groups. (C) The mice weight was measured every 4 days following treatments up until day 28 so as to measure side effect. The data represent the mean $\pm S D$. $* * P<0.0$ I significantly different vs 5 -FU. ${ }^{*} P<0.0$ I significantly different vs PBS.

Abbreviations: oHSV2, oncolytic herpes simplex virus type 2; PBS, phosphate-buffered saline; 5-FU, 5-fluorouracil; SD, standard deviation.

that develop chemotherapy or radiation resistance are still suitable targets for immunotherapy. ${ }^{37,38}$ There have been reports that CRC patients have increased levels of Tregs in peripheral blood and a high density of infiltrating Tregs in tumor tissues, which have been associated with a poor prognosis. ${ }^{39}$ As the same, increased MDSC levels are also a predictor of undesirable outcomes in colon cancer patients. Therefore, diminishing MDSCs and Tregs are a promising therapeutic strategies to reverse cancer-associated immune dysfunction. ${ }^{40}$ It has recently been reported that arming OVs with GM-CSF can support the attraction of immune effector cells to the tumor site, thereby improving the induction of a tumor-specific immune response. ${ }^{41}$ GM-CSF has been shown to be the most potent, specific, and long-lasting stimulator of systemic antitumor immunity that can enhance the efficacy of OVs. ${ }^{42}$ In our study, oHSV2 was successfully replicated and expressed of GM-CSF in tumor-bearing mice, and GMCSF was secreted into the blood from the tumor. Therefore, GM-CSF can also be detected in serum. The results show that GM-CSF was detected in blood on the 2nd day, subsequently peaked on day 8 after treatment, and then began to decrease.

To study the immunologic aspects of oHSV2, a fully immunocompetent mouse with a functional adaptive immune system was established that had a major impact on treatment outcome. In the present study, we analyzed the frequency of Tregs and MDSCs in murine spleens, which might reflect the overall immunologic status, with flow cytometry. Our data showed that 5-FU treatment slightly reduced the frequency of MDSCs and significantly enhanced the frequency of Tregs. It is well-known that the administration of anticancer chemotherapy is almost inseparably related to more or 
less long-lasting immunosuppression. ${ }^{43}$ Because of selective cytotoxic action on MDSCs, ${ }^{44}$ 5-FU treatment slightly reduced the frequency of MDSCs, but the therapeutic impact of 5-FU is not well-established. ${ }^{45}$ In contrast, oHSV2 treatment favorably enhanced the anticancer immune response by reducing Tregs and MDSCs. This result corresponds with T-VEC, which also decreases these two immunosuppressive cell types successfully in patients with stage IIIc and IV melanoma. ${ }^{46}$ The mechanism underlying this phenomenon is unclear and may result from release of tumor antigens and expression of GM-CSF ${ }^{47}$

The recombinant OV oHSV2 was used to introduce the GM-CSF gene directly into tumors, so that the cytokine was produced in situ, resulting in promoting the specific antitumor immune responses. In the present study, we evaluated DCs by flow cytometry using anti-CD11c and anti-CD86 antibodies at the TDLN. CD11c has been reported as a relatively restricted marker of murine DCs, ${ }^{48}$ and $\mathrm{CD} 86$ has been reported to be a costimulatory molecule of DCs. The level of DCs in TDLN can indirectly reflect the regulation of GM-CSF antitumor immune responses. The results from our study showed that the proportion of DCs was significantly enhanced. This finding may be due to direct injection of oHSV2 into established mice, resulting in local GM-CSF accumulation, which may attract and mature DCs. GM-CSF has been shown to play an important role in recruiting and maturing DCs. ${ }^{49}$ In turn, the DCs act as a powerful stimulators to present tumor antigens to $\mathrm{CD}^{+}{ }^{+} \mathrm{T}$-cells via $\mathrm{MHC}$ class II or to $\mathrm{CD} 8^{+} \mathrm{T}$-cells via MHC class I. The activated $\mathrm{T}$ cells show specific cytotoxic activity to the target cells and mediate tumor destruction. The data from our study showed that oHSV2 significantly enhanced the levels of $\mathrm{CD}^{+} \mathrm{T}$ and $\mathrm{CD}^{+} \mathrm{T}$ compared with controls. Our results are in agreement with other combined immune virotherapy approaches employing OVs encoding GM-CSF that have also successfully recruited the adaptive immune system. ${ }^{50-52}$ Thus, oHSV2 may induce tumor regression both through direct lytic effects following IT injection into tumors and through secondary induction of systemic antitumoral immunity in the context of virally mediated GM-CSF production. ${ }^{53}$ By comparison, both DCs and T lymphocytes were markedly reduced after 5-FU treatment. Like other chemotherapy regimens, 5-FU suppresses proliferating lymphocytes ${ }^{54}$ and does not keep the remaining MDSCs from suppressing the $\mathrm{T}$ cell proliferative response, though it can reduce the number of MDSCs. Taken together, we demonstrated that IT injection with oHSV2 in a murine CRC model resulted in a decrease of systemic Tregs and MDSCs as well as generation of tumor-specific T-lymphocyte responses that developed effective responses. Such immunologic changes might be due to cytokine production.

In the CT26 xenograft model, oHSV2 showed significantly higher tumor rates and prolonged the survival period of tumor-loaded mice compared to PBS. The antitumor effect was similar to 5-FU. These findings are consistent with the results of immunologic changes, suggesting enhanced antitumor activity of oHSV2. Although oHSV2 was highly attenuated and replication was restricted, the use of a virus still raises concerns about viral proliferation and dissemination. During the experimental period, the body weights of the mice in the virus groups were similar to the control group at the beginning, and then gradually and stably increased. At the later stages, the body weights slowly increased compared to the control group, but there was no statistical difference. Therefore, oHSV2 treatment of cancer does not cause weight loss in mice. In addition, no necrosis and ulceration were observed in the areas of the skin where the virus was injected and the mice were generally in good condition. Thus oHSV2 treatment has less side effects. ${ }^{55}$ During the experimental period, 5-FU showed excellent anticancer activity, but it also caused weight loss in mice due to associated toxicity, including severe myelosuppression, severe gastrointestinal reactions, and neurotoxicity. It is known that patients with weight loss have a worse outcome when undergoing chemotherapy. ${ }^{56}$

\section{Conclusion}

Collectively, the data from this study demonstrate the potent antitumor effects of an oncolytic HSV-2 expressing GM-CSF on various CRC cell lines and in a murine CRC model. oHSV2 causes an oncolytic effect and recruits adaptive immune responses for an enhanced therapeutic impact, which is promising in the treatment of CRC. There were some limitations to our study. First, the mechanisms of activity of oHSV2 are complex and it is unclear what contributes to the tumoricidal activities. Second, none of the animal tumors completely regressed in the present study, and all animals died due to excessive tumor growth. The extracellular matrix and antiviral response may restrict the virus distribution and replication, ${ }^{57}$ but this remains puzzling. Third, current technologies and mouse models cannot completely mimic the effects of oHSV2 in patients. Fourth, combining oncolytic agents and immunotherapy is not without controversy because the development of antitumor immunity would affect the clearance of OVs. Therefore, only preliminary findings were obtained in the present study; more thorough experimentation and understanding are needed to open new frontiers in the study of the mechanisms of action of oHSV2. 


\section{Acknowledgments}

This work was supported by grants from the Youth program of Shandong academy of medical sciences technology plan (2014-2026 and 2014-2061), the Science \& Technology Development Projects of Shandong Province (No 2013GSF11834), the projects of medical science and technology development in Shandong province (No 2015WS0149; 2015WS0197).

\section{Disclosure}

The authors report no conflicts of interest in this work.

\section{References}

1. Rosa B, de Jesus JP, de Mello EL, Cesar D, Correia MM. Effectiveness and safety of monoclonal antibodies for metastatic colorectal cancer treatment: systematic review and meta-analysis. Ecancermedicalscience. 2015;9:582.

2. Siegel R, Naishadham D, Jemal A. Cancer statistics, 2013. CA Cancer J Clin. 2013;63:11-30.

3. Cunningham D, Atkin W, Lenz HJ, et al. Colorectal cancer. Lancet. 2010; 375:1030-1047.

4. Ferlay J, Shin HR, Bray F, Forman D, Mathers C, Parkin DM. Estimates of worldwide burden of cancer in 2008: GLOBOCAN 2008. Int J Cancer. 2010;127:2893-2917.

5. Amin M, Lockhart AC. The potential role of immunotherapy to treat colorectal cancer. Expert Opin Investig Drugs. 2015;24(3): 329-344.

6. Van Cutsem E, Nordlinger B, Adam R, et al. Towards a pan-European consensus on the treatment of patients with colorectal liver metastases. Eur J Cancer. 2006;42(14):2212-2221.

7. Gallagher DJ, Kemeny N. Metastatic colorectal cancer: from improved survival to potential cure. Oncology. 2010;78:237-248.

8. Gomez GG, Hutchison RB, Kruse CA. Chemo-immunotherapy and chemo-adoptive immunotherapy of cancer. Cancer Treat Rev. 2001 27(6):375-402.

9. Bergers G, Hanahan D. Modes of resistance to anti-angiogenic therapy. Nat Rev Cancer. 2008;8(8):592-603.

10. Pol J, Kroemer G, Galluzzi L. First oncolytic virus approved for melanoma immunotherapy. Oncoimmunology. 2015;5(1):e1115641.

11. Russell SJ, Peng KW, Bell JC. Oncolytic virotherapy. Nat Biotechnol. 2012;30(7):658-670.

12. Fu X, Tao L, Zhang X. An oncolytic virus derived from type 2 herpes simplex virus has potent therapeutic effect against metastatic ovarian cancer. Cancer Gene Ther. 2007;14(5):480-487.

13. Duerst RJ, Morrison LA. Herpes simplex virus 2 virion host shutoff protein interferes with type I interferon production and responsiveness. Virology. 2004;322(1):158-167.

14. Fu X, Tao L, Cai R, Prigge J, Zhang X. A mutant type 2 herpes simplex virus deleted for the protein kinase domain of the ICP10 gene is a potent oncolytic virus. Mol Ther. 2006;13(5):882-890.

15. MacLean AR, ul-Fareed M, Robertson L, Harland J, Brown SM. Herpes simplex virus type 1 deletion variants 1714 and 1716 pinpoint neurovirulence-related sequences in Glasgow strain 17+ between immediate early gene 1 and the 'a' sequence. J Gen Virol. 1991;72(Pt 3): 631-639.

16. Leib DA, Harrison TE, Laslo KM, Machalek MA, Moorman NJ, Virgin HW. Interferons regulate the phenotype of wild-type and mutant herpes simplex viruses in vivo. J Exp Med. 1999;189(4): 663-672.

17. Kaufman HL, Bines SD. OPTIM trial: a Phase III trial of an oncolytic herpes virus encoding GM-CSF for unresectable stage III or IV melanoma. Future Oncol. 2010;6(6):941-949.
18. Kohno SI, Luo C, Nawa A, et al. Oncolytic virotherapy with an HSV amplicon vector expressing granulocyte-macrophage colony-stimulating factor using the replication-competent HSV type 1 mutant HF10 as a helper virus. Cancer Gene Ther. 2007;14(11):918-926.

19. Hwang TH, Moon A, Burke J, et al. A mechanistic proof-of-concept clinical trial with JX-594, a targeted multi-mechanistic oncolytic poxvirus, in patients with metastatic melanoma. Mol Ther. 2011;19(10): 1913-1922.

20. Hersey P, Gallagher S. Intralesional immunotherapy for melanoma. J Surg Oncol. 2014;109(4):320-326.

21. Stewart TJ, Abrams SI. How tumours escape mass destruction. Oncogene. 2008;27(45):5894-5903.

22. Battaglia A, Buzzonetti A, Baranello C, et al. Metastatic tumour cells favour the generation of a tolerogenic milieu in tumour draining lymph node in patients with early cervical cancer. Cancer Immunol Immunother. 2009;58(9):1363-1373.

23. Whiteside TL. The role of immune cells in the tumor microenvironment. Cancer Treat Res. 2006;130:103-124.

24. Ugel S, Delpozzo F, Desantis G, et al. Therapeutic targeting of myeloidderived suppressor cells. Curr Opin Pharmacol. 2009;9(4):470-481.

25. Zhao Q, Zhang W, Ning Z, et al. A novel oncolytic herpes simplex virus type 2 has potent anti-tumor activity. PLoS One. 2014;9(3):e93103.

26. Ciomei M, Croci V, Ciavolella A, Ballinari D, Pesenti E. Antitumor efficacy of edotecarin as a single agent and in combination with chemotherapy agents in a xenograft model. Clin Cancer Res. 2006;12(9): 2856-2861.

27. Nakamura K, Sasayama A, Takahashi T, Yamaji T. An immunemodulating diet in combination with chemotherapy prevents cancer cachexia by attenuating systemic inflammation in colon 26 tumorbearing mice. Nutr Cancer. 2015;67(6):912-920.

28. Sinha P, Chornoguz O, Clements VK, Artemenko KA, Zubarev RA, Ostrand-Rosenberg S. Myeloid-derived suppressor cells express the death receptor Fas and apoptose in response to T cell-expressed FasL. Blood. 2011;117(20):5381-5390.

29. Ottolino-Perry K, Acuna SA, Angarita FA, et al. Oncolytic vaccinia virus synergizes with irinotecan in colorectal cancer. Mol Oncol. 2015;9(8): 1539-1552.

30. Fu X, Rivera A, Tao L, Zhang X. An HSV-2 based oncolytic virus can function as an attractant to guide migration of adoptively transferred T cells to tumor sites. Oncotarget. 2015;6(2):902-914.

31. Bateman AR, Harrington KJ, Kottke T, et al. Viral fusogenic membrane glycoproteins kill solid tumor cells by nonapoptotic mechanisms that promote cross presentation of tumor antigens by dendritic cells. Cancer Res. 2002;62(22):6566-6578

32. Li H, Dutuor A, Fu X, Zhang X. Induction of strong antitumor immunity by an HSV-2-based oncolytic virus in a murine mammary tumor model. J Gene Med. 2007;9(3):161-169.

33. Hwang PM, Bunz F, Yu J, et al. Ferredoxin reductase affects p53dependent, 5-fluorouracil-induced apoptosis in colorectal cancer cells Nat Med. 2001;7(10):1111-1117.

34. Santi DV, McHenry CS, Raines RT, Ivanetich KM. Kinetics and thermodynamics of the interaction of 5-fluoro-2'-deoxyuridylate with thymidylate synthase. Biochemistry. 1987;26(26):8606-8613.

35. Sauter B, Albert ML, Francisco L, Larsson M, Somersan S, Bhardwaj N Consequences of cell death: exposure to necrotic tumor cells, but not primary tissue cells or apoptotic cells, induces the maturation of immunostimulatory dendritic cells. J Exp Med. 2000;191(3):423-434.

36. Alpizar YA, Chain B, Collins MK, et al. Ten years of progress in vaccination against cancer: the need to counteract cancer evasion by dual targeting in future therapies. Cancer Immunol Immunother. 2011;60(8): 1127-1135

37. Weng D, Song B, Koido S, Calderwood SK, Gong J. Immunotherapy of radioresistant mammary tumors with early metastasis using molecular chaperone vaccines combined with ionizing radiation. J Immunol. 2013; 191(2):755-763

38. Koido S, Homma S, Takahara A, et al. Current immunotherapeutic approaches in pancreatic cancer. Clin Dev Immunol. 2011;2011:267539. 
39. Bonertz A, Weitz J, Pietsch DH, et al. Antigen-specific Tregs control T cell responses against a limited repertoire of tumor antigens in patients with colorectal carcinoma. J Clin Invest. 2009;119(11):3311-3321.

40. Solito S, Falisi E, Diaz-Montero CM, et al. A human promyelocyticlike population is responsible for the immune suppression mediated by myeloid-derived suppressor cells. Blood. 2011;118(8):2254-2265.

41. Dempe S, Lavie M, Struyf S, et al. Antitumoral activity of parvovirusmediated IL-2 and MCP-3/CCL 7 delivery into human pancreatic cancer: implication of leucocyte recruitment. Cancer Immunol Immunother. 2012;61(11):2113-2123.

42. Dranoff G, Jaffee E, Lazenby A, et al. Vaccination with irradiated tumor cells engineered to secrete murine granulocyte-macrophage colonystimulating factor stimulates potent, specific, and long-lasting antitumor immunity. Proc Natl Acad Sci U S A. 1993;90(8):3539-3543.

43. Zagozdzon R, Golab J. Immunomodulation by anticancer chemotherapy: more is not always better (review). Int J Oncol. 2001;18(2):417-424.

44. Vincent J, Mignot G, Chalmin F, et al. 5-Fluorouracil selectively kills tumor-associated myeloid-derived suppressor cells resulting in enhanced T cell-dependent antitumor immunity. Cancer Res. 2010; 70(8):3052-3061.

45. Pernot S, Terme M, Voron $\mathrm{T}$, et al. Colorectal cancer and immunity: what we know and perspectives. World J Gastroenterol. 2014;20(14): $3738-3750$

46. Kaufman HL, Kim DW, DeRaffele G, Mitcham J, Coffin RS, Kim-Schulze S. Local and distant immunity induced by intralesional vaccination with an oncolytic herpes virus encoding GM-CSF in patients with stage IIIc and IV melanoma. Ann Surg Oncol. 2010;17(3): 718-730.

47. de Vries CR, Monken CE, Lattime EC. The addition of recombinant vaccinia HER2/neu to oncolytic vaccinia-GMCSF given into the tumor microenvironment overcomes MDSC-mediated immune escape and systemic anergy. Cancer Gene Ther. 2015;22(3):154-162.

48. Steinman RM. The dendritic cell system and its role in immunogenicity. Annu Rev Immunol. 1991;9:271-296.
49. Shi Y, Liu CH, Roberts AI, et al. Granulocyte-macrophage colonystimulating factor (GM-CSF) and T-cell responses: what we do and don't know. Cell Res. 2006;16(2):126-133.

50. Derubertis BG, Stiles BM, Bhargava A, et al. Cytokine-secreting herpes viral mutants effectively treat tumor in a murine metastatic colorectal liver model by oncolytic and T-cell-dependent mechanisms. Cancer Gene Ther. 2007;14(6):590-597.

51. Grossardt C, Engeland CE, Bossow S, et al. Granulocyte-macrophage colony-stimulating factor-armed oncolytic measles virus is an effective therapeutic cancer vaccine. Hum Gene Ther. 2013;24(7):644-654.

52. Andtbacka RH, Ross M, Puzanov I, et al. Patterns of clinical response with talimogene laherparepvec (T-VEC) in patients with melanoma treated in the OPTiM phase III clinical trial. Ann Surg Oncol. 2016;23(13):4169-4177.

53. Kaufman HL, Ruby CE, Hughes T, Slingluff CL Jr. Current status of granulocyte-macrophage colony-stimulating factor in the immunotherapy of melanoma. J Immunother Cancer. 2014;2:11.

54. Xie N, Wang Y, Wang Q, Li FR, Guo B. Lipoteichoic acid of Bifidobacterium in combination with 5 -fluorouracil inhibit tumor growth and relieve the immunosuppression. Bull Cancer. 2012;99(5):E55-E63.

55. Israyelyan A, Chouljenko VN, Baghian A, David AT, Kearney MT, Kousoulas KG. Herpes simplex virus type-1(HSV-1) oncolytic and highly fusogenic mutants carrying the NV1020 genomic deletion effectively inhibit primary and metastatic tumors in mice. Virol $J$. 2008;5:68.

56. Andreyev HJ, Norman AR, Oates J, Cunningham D. Why do patients with weight loss have a worse outcome when undergoing chemotherapy for gastrointestinal malignancies? Eur J Cancer. 1998; 34(4):503-509.

57. Zhuang X, Zhang W, Chen Y, et al. Doxorubicin-enriched, ALDH(br) mouse breast cancer stem cells are treatable to oncolytic herpes simplex virus type 1. BMC Cancer. 2012;12:549.
Therapeutics and Clinical Risk Management

\section{Publish your work in this journal}

Therapeutics and Clinical Risk Management is an international, peerreviewed journal of clinical therapeutics and risk management, focusing on concise rapid reporting of clinical studies in all therapeutic areas, outcomes, safety, and programs for the effective, safe, and sustained use of medicines. This journal is indexed on PubMed Central, CAS,

\section{Dovepress}

EMBase, Scopus and the Elsevier Bibliographic databases. The manuscript management system is completely online and includes a very quick and fair peer-review system, which is all easy to use. Visit http://www.dovepress.com/testimonials.php to read real quotes from published authors. 